\title{
Applying CRM in Information Product Pricing
}

\author{
Wenjing Shang, Hong Wu and Zhimin Ji \\ School of Economics and Management, Beijing University of Posts and \\ Telecommunications, Beijing100876,P.R. China shang_wj83@yahoo.com.cn \\ whong@263.net minies@126.com
}

\begin{abstract}
Since information products have unique cost structure and characteristics, namely, high fixed cost and low variable cost, the traditional pricing strategy based on marginal cost theory can not be applied by the producers. This paper indicates a new principle of pricing-customer value (CV) principle. Based on the principle, the producers can execute a number of different pricing strategies to maximize the $\mathrm{CV}$ in order to gain business profit. In this article, we focus on the capability of CRM (Customer Relationship Management) in this domain. CRM can help evaluate buyers, customize products and manage lock-in effects to implement CV. We first present an economic approach to analyze the market structure and pricing strategies, and then illustrate the CRM application models in the two pricing strategies which are based on Pigou's price discrimination framework. Finally, the conclusion indicates that CRM application in the information products pricing can benefit both customers and producers.
\end{abstract}

Keywords: CRM (Customer Relationship Management), Information products pricing, Customer value, Price differentiation

\section{INTRODUCTION}

As information providers begin to make their information available to the consumers in many more formats--paper, $\mathrm{CD}$, and online services via the Internet-they are asking themselves whether they should institute user fees for these services and how much they should charge. Information is in essence anything that can be digitalized --that is, can be coded to bytes [1].Unlike other industrial products, information products have unique cost structure, namely, high fixed cost which is mostly composed by sink cost and low variable cost $[1,2]$.Taking the software for example, the software company spends millions developing it, but a copy of the product costs little compared to the fixed cost. According to traditional pricing policy in microeconomics, the marginal cost pricing cannot be adapted to price information. Therefore, researches on the information pricing have become prevalent for both practitioner and academician. Sundararjan [3] analyzed optimal pricing and technological protection for a monopolist using price discrimination among customers willing to buy variable quantities of a digital product. Jae Nahm [4] investigated the information gatekeeper's optimal fee structure when sellers can price discriminatingly. Pricing strategies in the network economy based on the customer value were emphasized by Carl and Hal [1].

Please use the following format when citing this chapter:

Shang, W., Wu, H., Ji, Z., 2007, in IFIP International Federation for Information Processing, Volume 255, Research and Practical Issues of Enterprise Information Systems II Volume 2, eds. L. Xu, Tjoa A., Chaudhry S. (Boston: Springer), pp. 1407-1411. 
Meanwhile, as the business world has shifted from product focus to customer focus, managers have found that the enhancement of existing customer relations brought the benefit of profitable and sustainable revenue growth [5]. The conception of CRM has been studied by Alex, Danny, \& Wesley [6], who reviewed and analyzed process-, strategy-, philosophy-, capability-, and technology-based CRM perspectives. Keith and Ali [7] classified the definitions into two categories: strategic or operational and defined CRM as a set of business activities supported by both technology and processes that is directed by strategy and is designed to improve business performance in an area of customer management. They also identified seven core benefits to serve as value drivers in the model including improved ability to target profitable customers, customized products and services, individualized marketing messages, and improved pricing. Handen [8] considered that five dimensions (strategy, organization, technology, segmentation and process) are necessary to implement a CRM project effectively.

We integrate the pricing strategies and CRM to analyze the possibility and benefits of CRM application in the information pricing based on the customer value principle. We first present an economic approach to analyze the market structure and pricing strategies, and then illustrate the CRM application models in the two pricing strategies which are based on Pigou's price discrimination framework. Finally, the main findings of the analysis are presented along with the conclusion, which is followed by the future research suggestions.

\section{RESEARCH PROPOSITIONS}

\subsection{The Pricing Strategy for Information Products}

There exists two sustainable market structures in the ultimately analysis of information market. One is a market where exists one or two monopoly companies which can enjoy the dominance of pricing because of economy of scales such as Microsoft in software industry. The more popular market structure is the second one where the companies sell similar products which are different from each other to some extent. On the market every information provider has some monopoly power and meanwhile they must face the competence. Porter [9] indicated that whatever which market a company locates in, two classical competitive strategies work. One is to decrease cost to achieve a leading position; the other is to differentiate the products as much as possible. Though some companies enjoy monopoly power in their segment markets, differentiating their products is necessary to keep ahead. Differentiating a product gives its producer more pricing power and even a degree of monopoly. Therefore, differentiation is a core strategy for information providers.

Because the information providers' average cost curve is above marginal cost curve, the companies will incur loss if adopting marginal cost pricing. Product differentiation and cost based-on pricing strategy abandonment make us to find out a new principle of pricing which is built on the basis of value. Pricing according to the customer value (CV) which reflects the focus shifting to customers can implement the products value and maximize the profit for information providers. Customer value is 
the utility and satisfaction which the product brings to the customers. Differentiated products have different customer values. If a producer can create add-value which can bring more customer value to differentiate its information, the pricing based on value can increase profit for the company. Even though, different customers perceive the same information product different because they get various utilities and satisfaction. Pricing the same product differently according to the customer values can also promote the company's revenue. Therefore, the customer value principle requires executing pricing differentiation.

\subsection{CRM Application in the Pricing Strategies}

Though differentiation is a general strategy for the producers, there exist elaborate strategies for different conditions. Pigou's theory about price discrimination gives a criterion to classify the strategies which are adopted by the information providers.

\subsubsection{The Individualized Pricing}

If a firm can charge each customer the maximum price that the customer is willing to pay for each unit bought, it is called first-degree discrimination. To implement this policy, however, the seller must know each potential buyer's individual demand curve and be able to set different prices for every unit of the product. We call this pricing strategy individualized pricing.

Blatant price discrimination is illegal, but it is not illegal to price the products differently based on different demand characteristics which reflect customer value. CRM application in the pricing process can help to evaluate the customers' individual demand curve, depending on the information provided by CRM touch points. Nowadays CRM touch points involve call center, E-mail, internet, voice response systems, retail store front and service department. They reveal the fundamental information about the consumers, including their purchase histories, habits and additional demands for the product and so on. Moreover, the accurate pricing is typically achieved by the deployment and use of intelligent agents in CRM. The software agents used by CRM systems can estimate buyer preferences, valuations and product tastes by combining the information get form the touch points with different data mining models in data warehouse. Vendors can use the information provided by the CRM system to charge the customer the highest price that she is willing to pay. And they also obtain accurate information about individual buyers, and provide products, services and prices tailored precisely to each consumer's individual preferences to implement the customer value.

Because every customer is charged the maximum she is willing to pay for each unit, the entire customer surplus is extracted and all the opportunities for additional profit through changes in sales are exploited. The individualized pricing based on the knowledge of customer value provided by CRM can increase the amount of firm profit. For instance, many web portals use self reported customer information to place targeted advertisements, at a premium of $100 \%$ to $300 \%[10]$.

Furthermore, CRM establishes a channel of one-to-one marketing, which can serve the customers individually and prevent alternative deliveries between different prices among customers. 


\subsubsection{Group Pricing}

In practice, the third-degree discrimination is more common in which vendors can segment the customers into several groups according to their characteristics and charge a different incremental margin to each identifiable segment (with uniform pricing within each segment). A segment is a significant group of buyers within a larger market. The customers belonging to one group have similar features such as price sensitive, or quality sensitive. Charging different for each group is another optimal pricing strategy for information product providers. We call this pricing strategy group pricing.

What role can CRM play in the group pricing? An important aspect is that it can help the producers to improve the group segment. Similar to the analysis above, elaborate information about the customers such as age, gender, occupation, the reaction to the promotion are provided to the producers. Producers can classify the customers to different groups according to the information. For example, Li, Shue, \&Lee [11] developed a CRM systematic approach for a major ISP company in Taiwan to discover network usage behaviors of customers, which helps management to identify usage pattern and present personalized care for the groups.

The other aspect is that the CRM can target the group and charge different based on the customer value. There are three factors driving the vendors to execute group pricing: demand elasticity, externality and lock-in effect. Empirical research has indicated that different groups have systemic different price elasticity of demand. The data from CRM through touch points and data warehouse can assist to evaluate groups' elasticity. Konana et al. [12] present a nonparametric estimation technique that enables the estimation of consumer demand characteristics from their observed behavior. Information products such as software have network externality when a consumer's utility increases with the user number of the product. If a company can estimate the utility incurred by externality for each group, it will have more initiatives to price. What CRM can do is to understand the cause of externality, to estimate the benefit for the group and to price the product basing on the customer value. Lock-in effect is also popular in information markets because information consumption has higher switch cost than general goods. A customer has fewer incentives to change to another vendor if the switch cost is expensive. CRM can implement the switch cost management through interactions between company and groups. Moreover, one of the CRM objects is to improve customers' loyalty and satisfaction by contacting customers, providing more care to them. By promoting the loyalty of group, the company will execute better group pricing.

Though group pricing captures less CS than the first-degree price discrimination, considering the CRM application, the system can manage the lock-in effect and externality through interaction between customers and company, and make the producers more flexible and effective to price their products. The total gain is greater than the consumer surplus which is calculated from the economic approach. 


\section{CONCLUSIONS AND FUTURE RESEARCH}

This research analyses the CRM application in information product pricing. CRM can not only help to offer the made-to-order product to customers but also establish a favorable contact with them. As consumers utilize the information customized for them, their perceptions of what they are getting for the money, value equity, will improve. Therefore, CRM application leads to increase the customers' welfare by improving their experience of the products. Meanwhile, the producers capture the consumer surplus (CS) to promote their profits. Hence, CRM application can bring benefits for both consumers and sellers. It is necessary for the information product vendors to adopt CRM to price accurately and effectively.

The work can be further extended to adopt an empirical analysis to investigate the effects of CRM application in the pricing. The models should be established to illustrate the detailed application process in a company.

\section{REFERENCES}

1. C. Shapiro and H. Varian, Information Rules: A strategy Guide to the Network Economy (Harvard Business School Press: Boston, MA, 1999).

2. M. Khouja and M.A. Smith, Optimal pricing for information goods with piracy and saturation effect, European Journal of Operational Research.Volume176, pp.482-497, (2007).

3. A. Sundararjan, Management digital piracy: Pricing and protection, Information Systems Research. Volume15, Number3, pp.287-308, (2004).

4. J. Nahm, The gatekeeper's optimal fee structure when sellers can price discriminate, Economics Letters. Volume 80, pp.9-14, (2003).

5. Y. Lin, H.Y. Su, and S. Chien, A knowledge-enabled procedure for customer relationship management, Industrial Marketing Management. Volume 35, pp.446-456, (2006).

6. A.R. Zablah, D.N. Bellenger, and W.J. Johnston, An evaluation of divergent perspectives on customer relationship management: Towards a common understanding of an emerging phenomenon, Industrial marketing management. Volume 33, pp.475-489, (2004).

7. K.A. Richards and E. Jones, Customer relationship management: Finding value drivers, Industrial Marketing Management. (2006).

8. L. Handen, The three Ws of technology, in Customer relationship management- a strategic imperative in the world of e-business, eds. S.A. Brown (John Wiley and Sons Canada: Toronto, 2000).

9. M.E. Porter, Competitive Advantage (The Free Press: New York, NY, 1985).

10. R. Aron, A. Sundararajan, and S. Viswanathan, Intelligent agents in electronic markets for information goods: customization, preference revelation and pricing, Decision Support Systems. Volume 41, pp.764-786, (2006).

11. S.T. Li, L.Y. Shue, and S.F. Lee, Enabling customer relationship management in ISP services through mining usage patterns, Expert Systems with Applications. Volume 30, pp.621-632, (2006).

12. P. Konana, A. Gupta, and A.B. Whinston, Integrating user preferences and real-time workload in electronic commerce, Information Systems Research. Volume 11, Number 2, pp.177-196, (2000). 